\title{
Gene $C 2$ of the Monopartite Geminivirus Tomato yellow leaf curl virus-China Encodes a Pathogenicity Determinant That Is Localized in the Nucleus
}

\author{
Rene van Wezel, ${ }^{1}$ Huangting Liu, ${ }^{2}$ Po Tien, ${ }^{3}$ John Stanley, ${ }^{4}$ and Yiguo Hong ${ }^{1}$ \\ ${ }^{1}$ Department of Entomology and Plant Pathology, Horticulture Research International, Kent ME19 6BJ, U.K.; \\ ${ }^{2}$ Department of Biology, University of St. Andrews, Fife KY16 9ST, U.K.; ${ }^{3}$ Department of Virology, Institute \\ of Microbiology, Beijing 100080, China; ${ }^{4}$ Department of Virus Research, John Innes Centre, Colney, \\ Norwich NR4 7UH, U.K. \\ Submitted 9 February 2001; Accepted 18 May 2001.
}

Expression of the Tomato yellow leaf curl virus-China (TYLCV-C) $\mathrm{C} 2$ protein and green fluorescent protein (GFP) fused to the $\mathrm{C} 2$ protein (C2-GFP) in Nicotiana benthamiana from a Potato virus $X(\mathrm{PVX})$ vector induced necrotic ringspots on inoculated leaves as well as necrotic vein banding and severe necrosis on systemically infected leaves. The localization of GFP fluorescence in plant cells infected with PVX/C2-GFP and in insect cells transfected with Baculovirus expressing C2-GFP indicates that the TYLCV-C C2 protein is capable of shuttling GFP into plant and insect cell nuclei. Our data demonstrate that the TYLCV-C C2 protein may contribute to viral pathogenicity in planta and is nuclear localized.

Additional keywords: Begomovirus, Geminiviridae, putative transcriptional activator protein.

A viral disease of tomato in China, which is transmitted by the whitefly Bemisia tabaci was first reported in 1965 (Ke et al. 1965) and has since become a serious threat to tomato production. Several distinct whitefly-transmitted viruses belonging to the genus Begomovirus in the family Geminiviridae, referred to collectively as Tomato yellow leaf curl virus, cause devastating damage to cultivated tomato worldwide (Picó et al. 1996). On the basis of sequence comparison, the causative agent of the disease in China was identified as a distinct begomovirus species, Tomato yellow leaf curl virus-China (TYLCV-C) (Liu et al. 1998). TYLCV-C has a single genomic component that is organized similarly to other monopartite begomoviruses such as Tomato yellow leaf curl virus (TYLCV), Tomato yellow leaf curl virus-Sardinia (TYLCVS), Tomato leaf curl virus (ToLCV), and Ageratum yellow vein virus (Dry et al. 1993; Kheyr-Pour et al. 1991; Navot et al. 1991; Tan et al. 1995) (viruses are named according to Fauquet et al. 2000). The cloned TYLCV-C genomic DNA is infectious in tomato and Nicotiana benthamiana (P. Tien, un-

Corresponding author: Y. Hong; E-mail: yiguo.hong@ @ri.ac.uk published data). Little information is available concerning the $T Y L C V-C$ gene function, however, other than from comparisons with work on related monopartite begomoviruses.

Most begomoviruses, typified by African cassava mosaic virus (ACMV) and Tomato golden mosaic virus (TGMV), have bipartite genomes (DNA A, resembling the monopartite virus component, and DNA B). TGMV and ACMV transcriptional activator proteins (TrAP, also known as AL2 and AC2) regulate viral coat protein and movement protein expression (Brough et al. 1992; Groning et al. 1994; Haley et al. 1992; Hong et al. 1996; Sunter and Bisaro 1991; Sunter and Bisaro 1992; Sunter and Bisaro 1997). The monopartite begomovirus homolog $\mathrm{C} 2$ protein shares high amino acid sequence identity with TrAP and possesses a basic domain within its $\mathrm{N}$-terminal half, an acidic domain at the $\mathrm{C}$ terminus that has been implicated in transcriptional activation for TGMV, and a zinc finger motif between the two. Similar to TrAP, the TYLCV C2 protein exhibits sequence-nonspecific single-stranded and, to a lesser extent, double-stranded DNA binding activity, which is attributed to the zinc finger motif for TGMV (Hartitz et al. 1999; Noris et al. 1996; Sung and Coutts 1996). There is evidence that the ToLCV C2 protein is also involved in the regulation of coat protein expression (Dry et al. 2000). Genetic analysis of TYLCV-S suggests that $\mathrm{C} 2$ protein plays a role in virus systemic spread in planta, although the mechanism remains to be established (Wartig et al. 1997).

The expression of ACMV TrAP from a PVX vector produced a necrotic response in plants, and the protein may play a role in circumventing the host defense mechanism by suppressing gene silencing (Hong et al. 1997; Voinnet et al. 1999). It is not known, however, whether the C2 protein functions in a similar manner. To investigate this possibility, the TYLCV-C C2 protein was expressed in $N$. benthamiana plants with a PVX vector. The wild-type $\mathrm{C} 2$ protein coding sequence (402 nucleotides) and a mutant derivative were amplified by polymerase chain reaction (PCR) and cloned as ClaI-EagI fragments into the vector $\mathrm{p} 45 \mathrm{P} 46$ (unpublished data), which is a modified version of $\mathrm{pP} 2 \mathrm{C} 2 \mathrm{~S}$ (Baulcombe et al. 1995), to produce $\mathrm{PVX} / \mathrm{C} 2$ and $\mathrm{PVX} / \mathrm{mC} 2$, respectively. The mutant 
contained a stop codon (TGA) immediately downstream of the initiation codon. It should be noted that the wild-type and mutant have the potential to encode a truncated version of the C3 protein. Additionally, the green fluorescent protein (GFP) coding sequence (738 nucleotides) was isolated from TXS.GFPCP (Santa Cruz et al. 1996) as an EagI-BspEI fragment and fused in-frame to the wild-type and mutated $\mathrm{C} 2$ protein coding sequences to produce PVX/C2-GFP and PVX/mC2-GFP, respectively. The GFP coding sequence also was introduced as an EagI-BspEI fragment into p45P46 to produce PVX/GFP (Fig. 1). Sequences were confirmed by automatic sequencing of the recombinant plasmids.

RNA transcripts were produced by in vitro transcription from the recombinant PVX clones after linearization with SpeI. N. benthamiana plants inoculated with $\mathrm{PVX} / \mathrm{mC} 2$ tran-

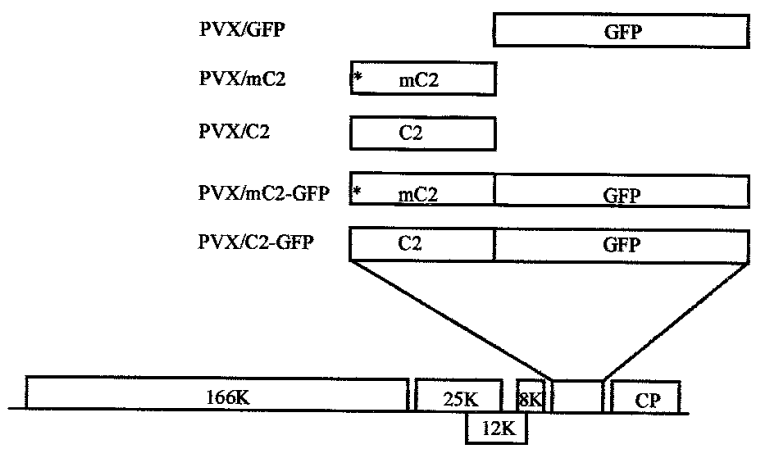

Fig. 1. Potato virus $X$-based expression cassettes. Expression of the inserted gene was under the control of one copy of the duplicated coat protein subgenomic RNA promoter. Stop codons (*) introduced in $m C 2$ and $m C 2-\mathrm{GFP}$ are indicated.
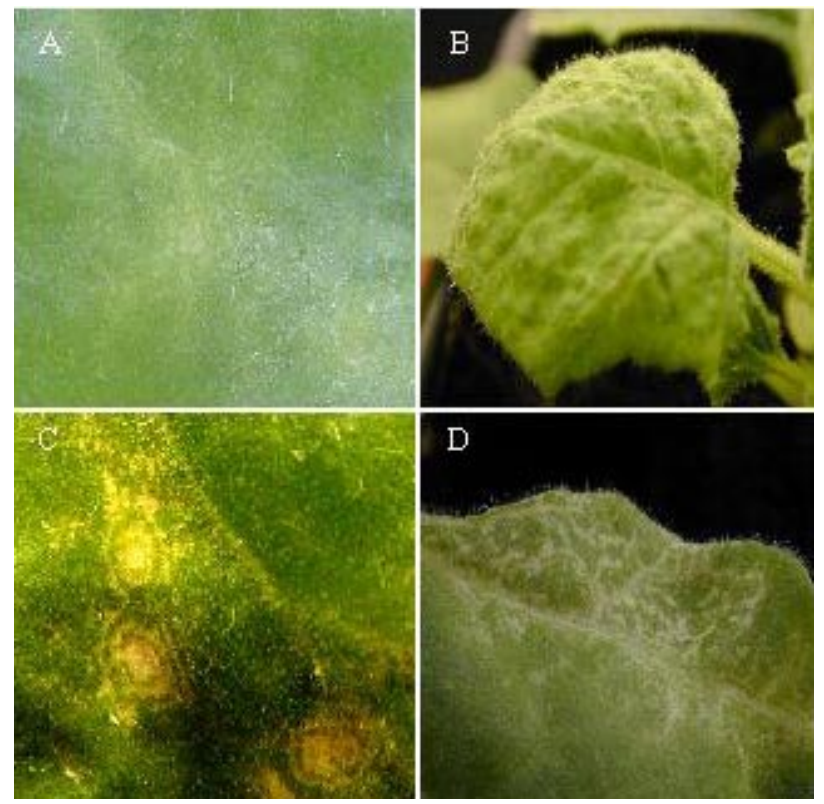

Fig. 2. Phenotypes produced in Nicotiana benthamiana infected with Potato virus $X(\mathrm{PVX}) / \mathrm{mC} 2$ and $\mathrm{PVX} / \mathrm{C} 2$. A, Chlorotic lesion on the inoculated leaf and $\mathbf{B}$, mosaic symptoms on a systemically infected leaf of a plant inoculated with $\mathrm{PVX} / \mathrm{mC} 2$. C, Necrotic ringspots on the inoculated leaf and $\mathbf{D}$, necrotic vein banding on a systemically infected leaf of a plant inoculated with PVX/C2. Plants were photographed 7 days postinoculation. scripts developed chlorotic lesions on the inoculated leaves 3 to 5 days postinoculation (dpi), and curling and mosaic symptoms on systemically infected leaves, which were indistinguishable from those seen in plants infected with the parental PVX vector, at 6 to 7 dpi. Plants inoculated with PVX/mC2GFP and PVX/GFP showed slightly milder chlorotic and mosaic symptoms, possibly as a result of the larger size of the replicating viral RNA. In contrast, plants inoculated with $\mathrm{PVX} / \mathrm{C} 2$ produced necrotic ringspots on the inoculated leaves at 3 to 4 dpi as well as necrotic vein banding on systemically infected leaves (Fig. 2). Interestingly, plants inoculated with PVX/C2-GFP expressing the C2-GFP fusion protein developed similar local and systemic necrosis. The results demonstrate that expression of the $\mathrm{C} 2$ protein rather than the overlapping truncated $\mathrm{C} 3$ protein is responsible for the induction of the necrotic phenotype and that the C-terminal GFP fusion has little effect on this phenotype. To confirm this, the coding sequence (258 nucleotides) for the truncated C3 was amplified by PCR with a primer (5'-GCTGTCACATCGATGATTCACGCACAG-3'; the C3 start codon is in bold and the ClaI site is underlined) and the $3^{\prime}$ end of the primer used for PCR amplification of the $C 2$ gene, and cloned as a ClaI-EagI fragment into $\mathrm{p} 45 \mathrm{P} 46$. Indeed, the truncated $\mathrm{C} 3$ protein did not induce

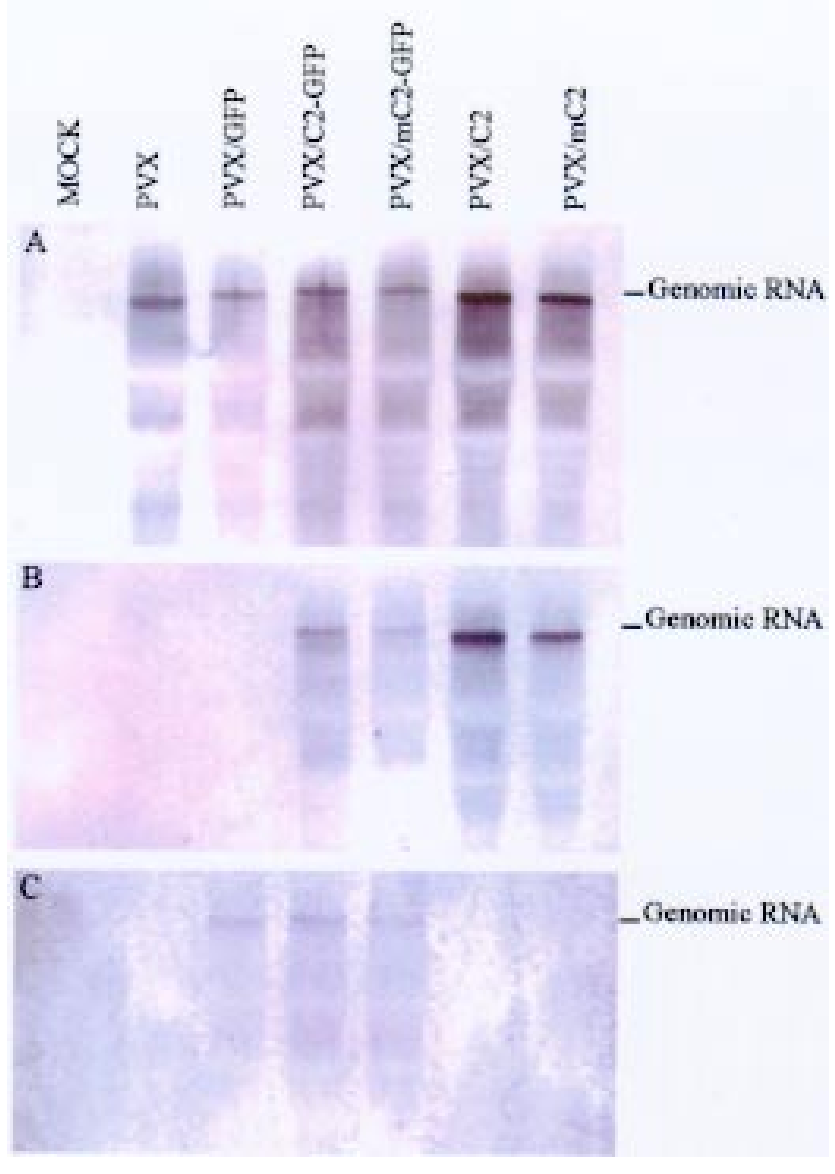

Fig. 3. Northern blot analysis of RNAs extracted 7 days postinoculation from mock-inoculated and virus-infected plants. Blots were hybridized with DIG-labeled probes specific to A, Potato virus $X, \mathbf{B}, A C 2, \mathbf{C}$, and green fluorescent protein sequences. Genomic RNA positions are indicated. 
necrosis when expressed from this PVX construct.

The presence of PVX RNAs in infected plants was investigated by Northern blot analysis. RNA was extracted from leaf tissues with the RNeasy plant mini kit (Qiagen, Hilden, Germany). RNA aliquots $(2.5 \mu \mathrm{g})$ were fractionated on $1 \%$ formaldehyde agarose gel, transferred to a nylon membrane, hybridized with DIG-labeled probes specific for PVX, $C 2$, or GFP sequences, and immunodetected with a DIG DNA labeling and detection kit (Roche Diagnostics, Mannheim, Germany). The accumulation of genomic RNAs containing the appropriate $C 2$ and GFP sequences was observed in systemically infected tissues (Fig. 3). To investigate gene expression from the PVX vectors, proteins were extracted from systemically infected tissues and fractionated on $12.5 \%$ polyacrylamide gel lacking sodium dodecyl sulfate. GFP was detected by UV illumination as described (Baulcombe et al. 1995). No fluorescence was observed in extracts from either mockinoculated plants or plants infected with PVX, PVX/mC2GFP, PVX/C2, or PVX/mC2 (Fig. 4). A fluorescent protein corresponding to GFP (approximately $27 \mathrm{kDa}$ ) was observed in extracts from plants infected with PVX/GFP, and a slower migrating fluorescent protein, consistent with the size of the C2-GFP fusion protein (approximately $40 \mathrm{kDa}$ ), was observed in extracts from plants infected with PVX/C2-GFP. The results indicate that functionally active GFP is expressed as a Cterminal fusion to the $\mathrm{C} 2$ protein, providing a convenient probe with which to investigate the cellular compartmentalization of the viral protein.

Systemically infected tissues from plants challenged with the various PVX-based constructs were examined by fluorescence microscopy (Fig. 5). Fluorescence was present throughout the cytoplasm of trichome and epidermal cells in plants infected with PVX/GFP (Fig. 5A, B, E, and F), but was localized predominantly in the nuclei of cells infected with PVX/C2-GFP (Fig. 5C, D, G, and H). This suggests that the C2 protein moiety relocates GFP to the nucleus. To substantiate this observation, C2-GFP was expressed transiently in insect Sf9 cells with a Bac-to-Bac Baculovirus expression system (Invitrogen Life Technologies, Groningen, The Netherlands). Once again, GFP fluorescence occurred throughout the

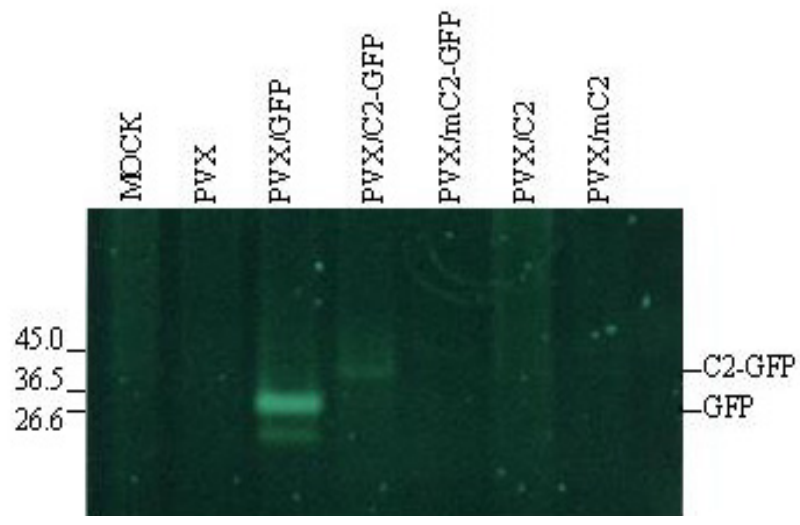

Fig. 4. Detection of green fluorescent protein fluorescence in plant extracts. Proteins were extracted 7 days postinoculation from a mockinoculated plant or plants infected with the Potato virus $X$-based constructs indicated. Aliquots $(100 \mu \mathrm{g})$ were fractionated by polyacrylamide gel electrophoresis and observed under UV illumination. Positions of size markers $(\mathrm{kDa})$ are indicated. cytoplasm, but C2-GFP fluorescence was confined primarily to the nucleus (Fig. 6), which is consistent with nuclear localization of the $\mathrm{C} 2$ protein. A nuclear localization signal has not yet been determined, but the basic domain between amino acids 17 and 31, KVQHRIAKKTTRRRR (the majority of the basic amino acids indicated in bold are highly conserved in begomoviruses), may contribute to this function.

Our data indicate that expression of the TYLCV-C C2 protein induces a necrotic response in plants, suggesting that it may function in gene silencing suppression, as demonstrated for the TrAP of the bipartite begomovirus ACMV (Voinnet et al. 1999). It is noteworthy that TYLCV-C infection of N. benthamiana is not reported to be associated with tissue necrosis. The fact that the C2-GFP fusion protein also induces a necrotic response indicates that the $\mathrm{C} 2$ protein moiety remains functionally active in this context and suggests that the observed nuclear localization of the fusion protein reflects the C2 protein function. Nuclear localization would be expected if the $\mathrm{C} 2$ protein is to fulfill its proposed function in transcriptional transactivation.

Bipartite begomovirus TrAP is nuclear localized (Sanderfoot and Lazarowitz 1995). Although ACMV AC2 protein expression from a PVX vector also induced a necrotic response in infected $N$. benthamiana (Hong et al. 1997), the two phenotypes are remarkably distinct. ACMV AC2 protein produced necrotic lesions on inoculated leaves and veinal necrosis on systemically infected leaves, whereas TYLCV-C C2 protein produced necrotic ringspots on inoculated leaves and necrotic vein banding on systemically infected leaves. Be-
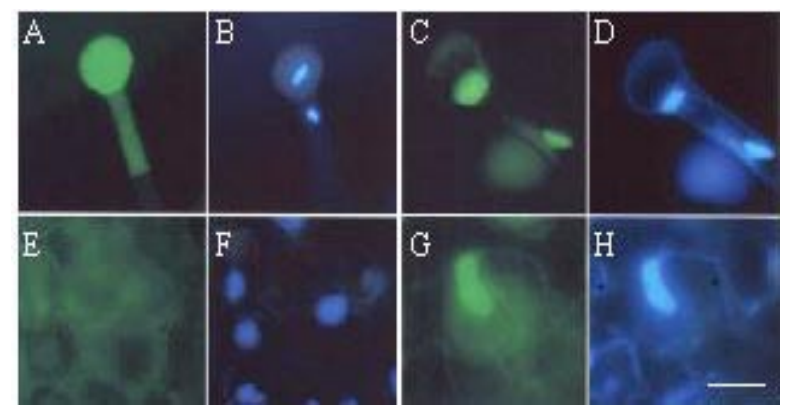

Fig. 5. Fluorescence microscopy of green fluorescent protein (GFP) localization in plant cells of systemically infected leaves at 7 days postinoculation. Trichome cells infected with $\mathbf{A}$ and $\mathbf{B}$, Potato virus $X$ $(\mathrm{PVX}) / \mathrm{GFP}$ and $\mathbf{C}$ and D, PVX/C2-GFP. Epidermal cells infected with $\mathbf{E}$ and $\mathbf{F}$, PVX/GFP and $\mathbf{G}$ and $\mathbf{H}, \mathrm{PVX} / \mathrm{C} 2-\mathrm{GFP}$. Samples were analyzed for A, C, E, and G, GFP fluorescence or by B, D, F, and H, 4'6diamidino-2-phenylindole staining. $\mathrm{Bar}=5 \mu \mathrm{m}$.
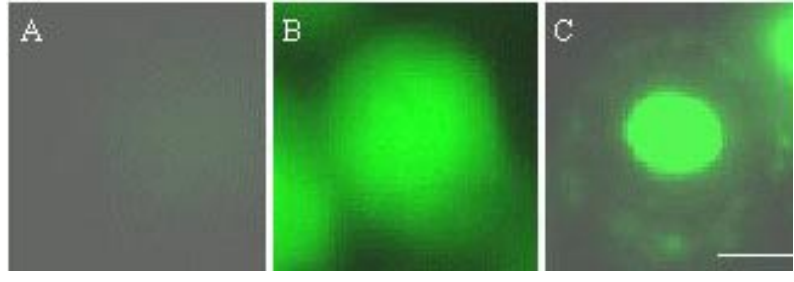

Fig. 6. Green fluorescent protein (GFP) localization in insect Sf9 cells by fluorescence microscopy. Cells were transfected with $\mathbf{A}$, empty Baculovirus vector or vectors expressing $\mathbf{B}, \mathrm{GFP}$ and $\mathbf{C}, \mathrm{C} 2-\mathrm{GFP}$. Bar = $10 \mu \mathrm{m}$. 
cause there is much variation in the extent of suppression of gene silencing by different viruses (Vionnet et al. 1999), this result might indicate that the ACMV AC2 protein triggers a more aggressive effect on plant defense mechanism, i.e., gene silencing than that triggered by the TYLCV-C C2 protein. Alternatively, the different plant responses might reflect functional differences between these gene homologs from monopartite and bipartite begomoviruses. Experiments to determine whether the TYLCV-C C2 protein also is able to suppress gene silencing are currently in progress. The analysis of $\mathrm{C} 2$ and $\mathrm{AC} 2$ mutants and recombinant proteins may identify the pathogenicity domains responsible for the induction of their distinct phenotypes.

\section{ACKNOWLEDGMENTS}

We thank D. Baulcombe for providing plasmid pP2C2S, S. Santa Cruz for providing plasmid TXS.GFP-CP, and C. Porta for comments on the manuscript. R. van Wezel and Y. Hong thank D. Parry and T. M. A. Wilson for their encouragement throughout the research. This work was supported in part by the Biotechnology and Biological Sciences Research Council.

\section{LITERATURE CITED}

Brough, C. L., Sunter, G., Gardiner, W. E., and Bisaro, D. M. 1992. Kinetics of tomato golden mosaic virus DNA replication and coat protein promoter activity in Nicotiana tabacum protoplasts. Virology 187:1-9.

Baulcombe, D. C., Chapman, S., and Santa Cruz, S. 1995. Jellyfish green fluorescent protein as a reporter for virus infection. Plant J. 7:1045-1053.

Dry, I. B., Rigden, J. E., Krake, L. R., Mullineaux, P. M., and Rezaian, M. A. 1993. Nucleotide sequence and genome organization of tomato leaf curl virus. J. Gen. Virol. 74:147-151.

Dry, I., Krake, L., Mullineaux, P., and Rezaian, A. 2000. Regulation of tomato leaf curl virus gene expression in host tissues. Mol. PlantMicrobe Interact. 13:529-537.

Fauquet, C. M., Maxwell, D. P., Gronenborn, B., and Stanley, J. 2000. Revised proposal for naming geminiviruses. Arch. Virol. 145:1743-1761.

Groning, B. R., Hayes, R. J., and Buck, K. W. 1994. Simultaneous regulation of tomato golden mosaic virus coat protein and AL1 gene expression: Expression of the AL4 gene may contribute to suppression of the AL1 gene. J. Gen. Virol. 75:721-726.

Haley, A., Zhan, X. C., Richardson, K., Head, K., and Morris, B. 1992. Regulation of the activities of African cassava mosaic virus promoters by the AC1, AC2 and AC3 gene products. Virology 188:905-909.

Hartitz, M. D., Sunter, D., and Bisaro, D. M. 1999. The tomato golden mosaic virus transactivator (TrAP) is a single-stranded DNA and zincbinding phosphoprotein with an acidic activation domain. Virology 263:1-14.
Hong, Y., Saunders, K., Hartley, M. R., and Stanley, J. 1996. Resistance of geminivirus infection by virus-induced expression of dianthin in transgenic plants. Virology 220:119-127.

Hong, Y., Saunders, K., and Stanley, J. 1997. Transactivation of dianthin transgene expression by African cassava mosaic virus AC2. Virology 228:383-387.

Ke, C., Sun, G. F., and Fan, H. C. 1965. A brief report of tomato yellow top disease in south China. Acta Phytophylacica Sin. 4:103.

Kheyr-Pour, A., Bendahmane, M., Matzeit, V., Accotto, G. P., Crespi, S., and Gronenborn, B. 1991. Tomato yellow leaf curl virus from Sardinia is a whitefly-transmitted monopartite geminivirus. Nucleic Acids Res. 19:6763-6769.

Liu, Y., Cai, J., Li, D. Qin, B., and Tien, P. 1998. Chinese tomato yellow leaf curl virus: A new species of geminivirus. Sci. China Ser. C 41:337-343.

Navot, N., Pichersky, E., Zeidan, M., Zamir, D., and Czosnek, H. 1991. Tomato yellow leaf curl virus: A whitefly-transmitted geminivirus with a single genome component. Virology 185:151-161.

Noris, E., Jupin, I., Accotto, G. P., and Gronenborn, B. 1996. DNAbinding activity of the $\mathrm{C} 2$ protein of tomato yellow leaf curl geminivirus. Virology 217:607-612.

Picó, B., Díez, M. J., and Nuez, F. 1996. Viral disease causing the greatest economic losses to the tomato crop II: The tomato yellow leaf curl virus-A review. Sci. Hortic. 67:151-196.

Sanderfoot, A. A., and Lazarowitz, S. G. 1995. Cooperation in viral movement: The geminivirus BL1 movement protein interacts with BR1 and redirects it from the nucleus to the cell periphery. Plant Cell 7:1185-1194.

Santa Cruz, S., Chapman, S., Roberts, A. G., Roberts, I. M., Prior, D. A. M., and Oparka, K. J. 1996. Assembly and movement of a plant virus carrying a green fluorescent protein overcoat. Proc. Natl. Acad. Sci. USA 93:6286-6290.

Sung, Y. K., and Coutts, R. H. A. 1996. Potato yellow mosaic geminivirus AC2 protein is a sequence non-specific DNA binding protein. FEBS Lett. 383:51-54.

Sunter, G., and Bisaro, D. M. 1991. Transactivation in a geminivirus: AL2 gene product is needed for coat protein expression. Virology 180:416-419.

Sunter, G., and Bisaro, D. M. 1992. Transactivation of geminivirus AR1 and BR1 gene expression by the viral AL2 gene product occurs at the level of transcription. Plant Cell 4:1321-1331.

Sunter, G., and Bisaro, D. M. 1997. Regulation of a geminivirus coat protein promoter by AL2 protein (Trap): Evidence for activation and derepression mechanisms. Virology 232:269-280.

Tan, P. H. N., Wong, S. M., Wu, M., Bedford, I. D., Saunders, K., and Stanley, J. 1995. Genome organization of ageratum yellow vein virus, a monopartite whitefly-transmitted geminivirus isolated from a common weed. J. Gen. Virol. 76:2915-2922.

Voinnet, O., Pinto, Y. M., and Baulcombe, D. C. 1999. Suppression of gene silencing: A general strategy used by diverse DNA and RNA viruses of plants. Proc. Natl. Acad. Sci. USA 96:14147-14152.

Wartig, L., Kheyr-Pour, A., Noris, E., Kouchkovsky, D. F., Jouanneau, F., Gronenborn, B., and Jupin, I. 1997. Genetic analysis of the monopartite tomato yellow leaf curl geminivirus: Roles of V1, V2, and C2 ORFs in viral pathogenesis. Virology 132-140. 